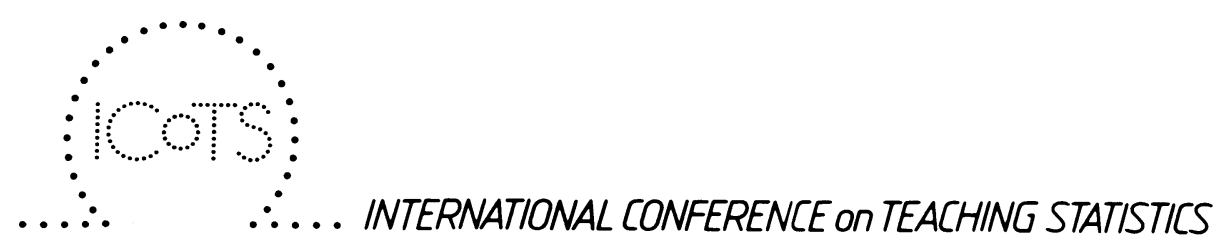

\title{
PRELIMINARY ANNOUNCEMENT
}

The International Statistical Institute is pleased to announce that the first International Conference on Teaching Statistics will be held in Sheffield, England, from 8-13 August 1982. For a copy of the first announcement write to:

The Conference Secretary,

International Conference on the Teaching

of Statistics,

Department of Probability and Statistics,

The University,

Sheffield S3 7RH,

England.

The objective of the conference is to improve the quality of statistics teaching on a world-wide basis. Key goals include fostering international co-operation among teachers of statistics and promoting the interchange of ideas about teaching materials, methods and content. Speakers of international repute will address the plenary meetings and present invited lectures. There will also be many workshops, discussion groups and contributed paper sessions. Teaching from the school to the college level as well as other forms of teaching will be included. There will also be sessions on teaching statistics to government and industrial practitioners. The conference is sponsored by the International Statistical Institute.

The Chairman of the local organizing committee is Professor Vic Barnett (University of Sheffield, England). The Chairman of the Programme Committee is Professor Lennart Råde (Chalmers University of Technology, Gothenburg, Sweden). Other members of the Programme Committee are Peter Holmes (University of Sheffield, England), Brian L. Joiner (University of Wisconsin, U.S.A.), Murthy N. Murthy (Statistical Institute for Asia and the Pacific, Tokyo, Japan), Boyan I. Penkov (University of Sofia, Bulgaria), Gottfried E. Noether (University of Connecticut, U.S.A.), John O. Oyelese (University of Ibadan, Nigeria), Ryszard Zielinski (Polish Academy of Sciences, Warsaw). 